\title{
Questão urbana e habitacional e Pós-Graduação em Serviço Social no Brasil
}

\author{
Urban and housing issue and Post-Graduation in Social Work in Brazil
}

Joana Valente Santana*

\section{Resumo:}

O presente artigo discute a ocorrência da questão urbana e habitacional no âmbito da PósGraduação em Serviço Social no Brasil, nos últimos cinco anos, com base nos temas dos Grupos de Pesquisa, disciplinas ofertadas e produção acadêmica discente nos Programas de Pós-Graduação da Área de Serviço Social. Como procedimento metodológico realizou-se um levantamento na Plataforma Sucupira/CAPES (período de 2013 a 2017) para coleta de dados nos relatórios dos 34 PPG/Serviço Social, com ênfase nas "Disciplinas" e "Trabalhos de Conclusão" (mestrado e doutorado), bem como na página do CNPq para levantamento dos Grupos de Pesquisa. Os resultados apontam que: a) na Plataforma Lattes existem 24 grupos com o tema da questão urbana e habitacional; b) que os dados disponíveis nos Relatórios dos 34 PPG registram 17 disciplinas ofertadas sobre o tema, sendo Milton Santos o autor mais indicado para leitura nessas disciplinas; c) dos 2.545 trabalhos de conclusão de curso cadastrados (de 2013 a 2017), 3,6\% (91) tratam da questão urbana e habitacional; d) desses 91 trabalhos de conclusão, 80,2\% enfatizam especificamente o tema da habitação e $21 \%$ fazem articulação com a atuação profissional do Assistente Social. A pesquisa na área urbana e habitacional está em consonância com o projeto éticopolítico do Serviço Social brasileiro.

Palavras-Chave: Questão urbana. Questão da habitação. Pós-Graduação em Serviço Social.

\begin{abstract}
This article discusses the ocurrence of the urban and housing issue in the scope of the PostGraduation in Social Work in Brazil, in the last five years, based on the themes of the Research Groups, offered subjects and academic student production in the Postgraduate Programs of the Area of Social Work. As a methodological procedure, a survey was carried out in the Sucupira / CAPES Platform (period from 2013 to 2017) for data collection in the reports of the 34 PPG / Social Work, with emphasis on "Disciplines" and "Conclusion Works" (masters and doctorates), as well as in the page of the CNPq for survey of the Research Groups. The results indicate that: a) in the Lattes Platform there are 24 groups with the urban and housing issue; b) that the data available in the Reports of the 34 PPG register 17 subjects offered on the subject matter, Milton Santos being the most suitable author for reading in these disciplines; c) of the 2,545 registered graduation projects (from 2013 to 2017), 3.6\% (91) address urban and housing issues; d) of these 91 completion projects, $80.2 \%$ specifically emphasize the housing issue and $21 \%$ articulate with the professional work of the Social Worker. Research in the urban and housing area is in line with the ethical-political project of the Brazilian Social Work.
\end{abstract}

Keywords: Urban issue. Housing issue. Post-Graduation in Social Work.

\footnotetext{
* Doutora em Serviço Social pela Universidade Federal do Rio de Janeiro. Professora Associada II do Programa de Pós-graduação em Serviço Social e da Faculdade de Serviço Social da Universidade Federal do Pará. Coordenadora Adjunta da Área de Serviço Social na CAPES (2018-2022). E-mail: joanavalente@ufpa.br/ joanavs@terra.com.br.
} 


\section{Introdução}

O presente artigo tem por objetivo apresentar uma reflexão sobre a questão urbana e habitacional no âmbito da pós-graduação em Serviço Social no Brasil, nos últimos cinco anos, no sentido de contribuir com as discussões desse tema no âmbito da formação em nível de graduação e pós-graduação em consonância com o Projeto Ético-Político do Serviço Social. A reflexão toma por base os temas dos Grupos de Pesquisa no Brasil, as disciplinas ofertadas e a produção acadêmica discente nos Programas de Pós-Graduação da Área de Serviço Social.

Os dados apresentados no estudo resultam de um levantamento realizado na Plataforma Sucupira, da Coordenação de Aperfeiçoamento de Pessoal de Nível Superior (CAPES), no período de 2013 a $2017^{1}$, onde foram pesquisados, tabulados e analisados dados referentes aos relatórios enviados a essa agência pelos 34 Programas de Pós-Graduação², área de avaliação Serviço Social ${ }^{3}$. Em cada Relatório, foram abertas e recolhidas as informações dos itens "Disciplinas" e "Trabalhos de Conclusão", em nível de mestrado e doutorado 4 .

Em relação às disciplinas, foram recolhidas informações referentes a: nome, ementa, referências bibliográficas e natureza (eletiva ou obrigatória). Em relação aos trabalhos de conclusão de curso, foram coletadas as informações sobre o título do trabalho, resumo, palavras-chave e nível (mestrado ou doutorado). Na sequência, os dados foram organizados em planilha eletrônica para facilitar a síntese dos dados e a elaboração de gráficos e quadros com os dados que serão apresentados na sequência deste artigo.

Complementarmente a esse levantamento, foi realizada uma sondagem na plataforma Lattes, do Conselho Nacional de Desenvolvimento Científico e Tecnológico

\footnotetext{
${ }^{1}$ A partir de 2013 os dados sobre os Programas de Pós-Graduação passaram a ser coletados na Plataforma Sucupira/Capes, motivo pelo qual escolheu-se esse ano para início do levantamento de dados para efeito deste artigo, e por entendermos que o período de cinco anos é considerável para a análise.

${ }^{2}$ A lista dos 34 Programas de Pós-Graduação foi retirada do Relatório de Avaliação 2013-2017/Quadrienal 2017 (CAPES, 2017).

3 Ressalte-se que o levantamento foi realizado da seguinte forma: na Plataforma Sucupira (https://sucupira.capes.gov.br/sucupira/), foi aberto o item Coleta Capes, seguido do item Dados do Envio. Após aberta esta aba (Dados de Envio), foram levantados os dados do Relatório de cada Programa, acionando os itens Calendário (Coleta de Informações, Instituição de Ensino Superior e Programa), sendo coletadas as informações ano a ano $(2013,2014,2015,2016,2017)$.

4 As palavras-chave que orientaram a pesquisa nos itens "Disciplinas" e "Trabalhos de Conclusão" foram: "espaço urbano", "questão urbana", "urbano", "política urbana”, "urbanização", "habitação", "questão habitacional", "política habitacional", "cidade", "moradia", "território".
} 
(CNPq/Diretório dos Grupos de Pesquisa no Brasil) no sentido de identificar grupos relacionados ao tema da questão urbana e habitacional ${ }^{5}$.

Os resultados do levantamento serão apresentados em duas seções. A primeira apresenta uma reflexão teórica sobre a produção da cidade e a desigualdade no acesso à habitação e incorporação do tema na agenda do Serviço Social. A segunda seção expõe o levantamento dos dados, dando ênfase aos grupos de pesquisa que estudam a temática urbana e habitacional e à formação profissional, por meio das disciplinas ofertadas na pósgraduação; e aos trabalhos de conclusão de curso dos discentes de mestrado e doutorado. Ao final do texto, são apresentadas as considerações finais.

\section{A questão urbana e habitacional}

O Serviço Social brasileiro vem avançando consideravelmente nos estudos das determinações das condições de vida dos/as trabalhadores/as, e especialmente nos estudos sobre as expressões da questão social, sendo considerado por Mota (2016) como área do conhecimento e profissão interventiva ${ }^{6}$. Considera-se que o avanço da produção do conhecimento da área de Serviço Social está articulada à vida concreta da atuação profissional nos mais variados campos de atuação, ou seja, a pesquisa pulsa da realidade social onde se insere o profissional de Serviço Social; daí não só a ampliação, mas a relevância social dessa pesquisa que tem se esforçado em evidenciar a monumental contradição de classe inscrita na realidade brasileira (mediada pela crise mundial do capitalismo) e o papel do Estado nessa contradição, via políticas sociais, onde atua a maioria dos profissionais de Serviço Social.

Dentre as expressões da questão social que vêm sendo estudada pelos pesquisadores do Serviço Social brasileiro estão a questão urbana e habitacional, articuladas aos estudos sobre as políticas urbanas e habitacionais, produção do espaço, movimentos

\footnotetext{
${ }^{5}$ A identificação desses grupos foi feita na página do CNPq (http://lattes.cnpq.br/web/dgp), mediante busca com a indicação de palavras chave (informadas na nota de rodapé número 05), indicação dos campos "Nome do grupo", "Nome da linha de pesquisa", "Palavra-chave da linha de pesquisa"; aplicação dos filtros: "Grande área: Ciências sociais aplicadas" e "Área: Serviço Social".

${ }^{6}$ Nestes termos, afirma a autora: "Conclusivamente, defendo que o Serviço Social brasileiro, historicamente, construiu uma cultura profissional a partir do exercício profissional, no âmbito do processo ampliado de reprodução social, mas nele não encerrou sua função ideopolítica. Considero que, nas três últimas décadas, o Serviço Social ampliou sua função intelectual, construindo uma massa crítica de conhecimentos, tributária da formação de uma cultura que se contrapõe à hegemonia dominante, protagonizada pela esquerda marxista no Brasil, e o fez sem perder a relação de unidade com o exercício profissional, mas expondo uma distinção entre o significado e a dimensão do Serviço Social como área do conhecimento e profissão voltada para a intervenção direta na realidade" (MOTA, 2016, p. 179).
} 
sociais urbanos, dentre outros. O Grupo Temático de Pesquisadores (GTP) Questões Agrária, Urbana e Ambiental ${ }^{7}$ e Serviço Social da ABEPSS (Associação Brasileira de Ensino e Pesquisa em Serviço Social) é uma demonstração de que a profissão vem se preocupando em debater, no âmbito da formação, a questão da habitação articulada às ênfases da questão agrária, urbana e ambiental.

Ressalta-se também que o Conselho Federal de Serviço Social vem pautando em suas discussões o tema do trabalho profissional nas políticas urbanas, tendo publicado, em 2016, a cartilha "Atuação de assistentes sociais na Política Urbana: subsídios para reflexão" (CFESS, 2016). Além disso o CFESS, no ano de 2014, lançou a campanha "Na Copa, comemorar o quê?, onde o documento CFESS Manifesta destacava que:

[...] se as cidades são arenas da luta de classes, as/os trabalhadores/as lá estarão para manifestar e apresentar suas reivindicações. E a nós, assistentes sociais, cabe a difícil tarefa de manter o compromisso ético e político pela defesa dos/as trabalhadores/as, dos direitos e não sucumbir à lógica destrutiva do capital. Reafirmamos nosso projeto ético-político comprometido com a garantia inalienável dos direitos humanos, da democracia e da superação da ordem social capitalista desigual e excludente, na perspectiva de cidades justas [...] (CFESS, 2014).

Autores clássicos e contemporâneos, de perspectiva crítica, têm dado suporte aos estudos da área de Serviço Social, a exemplo de Engels (1975), Lefebvre (1999), Lojkine (1997), Harvey (2005), Topalov (1996), Maricato (2001), Santos (1993). Tais autores expõem a histórica desigualdade social e econômica na apropriação e no uso do solo no modo de produção capitalista.

Na produção e reprodução do espaço urbano capitalista, questiona-se: qual o lugar da reprodução social dos trabalhadores pobres na cidade? Os lugares que o capital ainda não elegeu para obtenção de lucro.

Como assinala Topalov (1996), desde o início do século XX, os pobres, ou as "classes perigosas" ocupam as periferias dos centros urbanos. Isso porque a produção do espaço urbano é orientada pela lógica privada da terra e propriedade, motivo pelo qual, as frações de classe trabalhadora empobrecida disputam lugares para produção da vida social em favelas, encostas, baixadas, áreas de risco etc.

\footnotetext{
${ }^{7}$ A autora deste artigo vem atuando como membro da Coordenação desse GTP na gestão 2015/2016 e na atual, 2017/2018.
} 
Em tempos recentes, registra-se uma expansão da fração do capital imobiliário com o apoio irrestrito do Estado, conformando um processo de renovação urbana, caracterizado por um processo generalizado de intervenções físicas urbanas e deslocamento de pessoas, famílias e grupos sociais, em favor da potencialização econômica das áreas (DINIZ, 2013). Os eventos esportivos (a exemplo da Copa do mundo ${ }^{8}$ e Jogos Olímpicos no Brasil) e grandes projetos de infraestrutura física são exemplos de situações onde se dá essa modalidade de expansão do capital imobiliário em nível mundial e no Brasil.

Articulado a um modelo de gestão de cidades (amplamente propagado pelo Banco Interamericano de Desenvolvimento/BID), é preciso vender a imagem da cidade limpa, bela, eficiente para atrair os turistas (SANTANA, 2013) ${ }^{9}$. Desta forma, os governos nacionais e locais têm a necessidade de mascarar a violência e a pobreza nas cidades (As UPPs/Unidades de Polícia Pacificadora no Rio de Janeiro são exemplos dessa modalidade de intervenção do Estado).

Assim, há uma tendência mundial de intensificação do uso do espaço para fins do lucro capitalista, com a premissa do embelezamento de cidades, seja pela via dos megaeventos ou pela criação de grandes projetos de infraestrutura física, como exemplo, tem-se a reutilização das docas em Dublin/Irlanda, Puerto Madero/Argentina, Estação das Docas de Belém, Porto Maravilha /Rio de Janeiro etc. Como afirma Diniz (2013, p. 224) as "cidades reproduzem imagens arquitetônicas idealizadas pelo capital, numa representação da cidade globalizada".

Nesse contexto, o Estado capitalista atua como suporte para o financiamento da produção da infraestrutura física e social, elemento imprescindível, segundo Harvey (2005) para a circulação do capital. O Estado, ao organizar os interesses diferenciados das frações

\footnotetext{
${ }^{8}$ Sobre os gastos com a copa do mundo realizada em 2014, no Brasil, afirmaram Santos Junior e Santos, (2013, p. 15): "Do total de recursos previstos na Copa, $R \$ 9,8$ bilhões são financiamentos do governo federal para os governos locais (estaduais e municipais) e para a iniciativa privada". "O BNDES é o principal órgão financiador da Copa, seguido da CEF". E seguem afirmando: "A Copa do Mundo no Brasil deve ser a mais lucrativa para a FIFA em sua história, com a expectativa de um faturamento de 3,8 bilhões de dólares (R\$ 7,6 bilhões), US\$ 600 milhões a mais do que a receita gerada na Copa de 2010 (África do Sul), e quase o triplo da receita da Copa de 2006 (Alemanha). (SANTOS JUNIOR; SANTOS, 2013, p. 20).

${ }^{9}$ Em outro lugar, ao tratar sobre o financiamento de projetos urbanos, pelo BID, na cidade de Belém, afirmei que: "O estudo da lógica e da operacionalidade dos projetos de moradia (a exemplo do Promaben) evidencia o significado do modelo de gestão orientado pelo BID e aplicado, com anuência do Estado, nos países latinoamericanos. Alguns espaços da cidade são escolhidos para implantação de infraestrutura física e destinados às empresas capitalistas, ao turismo e/ou aos grandes eventos (como a Copa do Mundo). Para tanto, o Estado indeniza ou remove as pessoas pobres para conjuntos habitacionais, implicando frequentemente na piora das condições de vida dessas pessoas. Há pouca preocupação, seja do BID, seja do Estado com a permanência ou com o nível de satisfação das pessoas nas novas unidades habitacionais. Na maioria das vezes, o que permanece é a infraestrutura física, não as pessoas pobres" (SANTANA, 2012, p. 27-28).
} 
de classe dominante, necessariamente precisa contribuir com a produção da infraestrutura física e social indispensável às empresas capitalistas, local por excelência da produção da mais-valia, ao mesmo tempo em que contribui com o processo de financeirização da economia. Assim, o Estado capitalista caracteriza-se hoje clara e objetivamente, pelo avanço da programática neoliberal (na sua forma ultraconservadora), que economiza em todos os quadrantes com a reprodução social dos trabalhadores - face aos interesses das empresas capitalistas e investidores financeiros - mediante uma lógica setorizada e focalizada das políticas sociais, com baixa quantidade e qualidade de atendimento à classe trabalhadora.

Essa situação, somada ao desemprego estrutural, o crescente aviltamento das condições de trabalho e remuneração, bem como a destruição dos direitos trabalhistas agrava enormemente as condições de vida da classe trabalhadora empobrecida.

No âmbito urbano, importa registrar as expressões da questão social, onde a lógica da expansão da fração do capital imobiliário é cada vez mais prejudicial aos trabalhadores, com a intensificação da lógica mercadológica do uso do espaço urbano, que inviabiliza radicalmente a aquisição da moradia, por parte da classe trabalhadora, em espaços equipados, expressando uma cidade altamente desigual no acesso aos serviços urbanos, crescimento da violência urbana com aumento exponencial de mortes de jovens negros e pobres, pelo tráfico de drogas, milícias e a própria polícia. Dificuldade de pagamento de taxas de serviços e impostos para moradores que residem próximo aos empreendimentos imobiliários; perda de atividades ocupacionais e empobrecimento de moradores reassentados ou remanejados por projetos urbanísticos, dentre outros. Assim,

\footnotetext{
A produção do déficit habitacional do Brasil está diretamente ligada ao padrão desigual, espoliador e conservador do processo de modernização da sociedade brasileira e de seu desenvolvimento capitalista. As formas de seu enfrentamento exigem mais do que capacidade de planejamento de procedimentos regulatórios e urbanísticos e de gestão de recursos. É necessário que o direito à cidade ocupe a esfera pública de debate e deliberação como questão pertinente à vida urbana e, neste sentido, politize as avassaladoras desigualdades existentes na forma capitalista de produção do espaço urbano. Sem a criação de esferas públicas através das quais a sociedade possa romper a aparente ordem das coisas, com a fala e a ação, os marcos legais de regulamentação da política urbana estarão fadados ao descumprimento. A denúncia de tal risco pode ser verificada, por exemplo, quando o movimento dos sem-teto irrompe à cena pública das cidades e demonstra os limites reais da forma burguesa do direito, no caso, do direito à moradia, ao afirmar que "se morar é um direito ocupar é um dever" (CARDOSO, 2012, p. 41).
} 
No desenho da produção da cidade, um elemento tem se destacado como parte constitutiva do processo histórico de execução de projetos urbanísticos e habitacionais no Brasil: a remoção de moradores ${ }^{10,11}$. Remoção que se vincula à implantação de projetos de infraestrutura (saneamento ambiental, vias urbanas, transporte metroviário etc.) com retirada dos moradores e o consequente reassentamento para conjuntos habitacionais distantes dos centros urbanos ou recebimento de indenizações (que em geral são pagos com valores baixos). Registram-se ainda, remoções temporárias para construção de unidades habitacionais em áreas insalubres e de alto risco ${ }^{12}$,

Ao longo da história da política habitacional brasileira, os programas de erradicação e remoção de favelas sempre permearam a intervenção do Estado, especialmente, no período dos governos militares. As práticas executadas buscavam retirar os moradores dos núcleos centrais das cidades, em um primeiro momento, sem darIhes alternativas substitutivas de moradia. Posteriormente, essa população desalojada era transferida para os conjuntos habitacionais construídos em áreas distantes e isoladas (SOUZA, 2011, p. 53).

Os profissionais de Serviço Social têm sido requisitados para atuação em projetos urbanísticos e habitacionais - na composição de equipes de trabalho social - tendo que atuar, dentre outros, em processos que envolvem remoções de moradores ${ }^{13}$ e vivem, cotidianamente, o desafio de uma atuação que, contraditoriamente, atue em defesa do direito à cidade (pela orientação do projeto ético-político da profissão), estando, ao mesmo

10 No caso da realização da Copa do Mundo, no Brasil, aproximadamente 170 mil pessoas passaram por processos de remoções, inclusive com o tratamento violento dado pelo Estado e por empresas privadas aos moradores na remoção. Somente no Rio de Janeiro, mais de 19.000 famílias foram removidas por conta da necessidade de construção das obras para a realização do evento (ANCOP, 20--).

11 Para Denaldi (2009) a remoção de moradores compreende tanto ao reassentamento (ou realocação) ou remanejamento (ou relocação). O reassentamento caracteriza-se pela "remoção para outro terreno, fora do perímetro da área de intervenção. Trata-se da produção de novas moradias de diferentes tipos (apartamentos, habitações evolutivas, lotes urbanizados) destinadas aos moradores removidos dos assentamentos precários consolidáveis ou não consolidáveis". Quanto ao remanejamento, "Trata-se da reconstrução da unidade no mesmo perímetro da favela ou do assentamento precário que está sendo objeto de urbanização. A população é mantida no local após a substituição das moradias e do tecido urbano. É o caso, por exemplo, de áreas que necessitam de troca de solo ou aterro. Na maioria das vezes, a solução é a remoção temporária das famílias para execução de obras de infraestrutura e construção de novas moradias" (DENALDI, 2009, p. 115-116).

12 Não é propósito deste artigo, desenvolver argumentos sobre a política urbana e habitacional no Brasil, mas registram-se autores que têm se dedicado a esse tema, com enfoque nas remoções de moradores: Bonduki (1994), Bonduki e Rolnik (1979), Villaça (1986), Silva (1989), Valladares (1980, 1983, 2005), Maricato (1979), dentre outros.

${ }^{13}$ Remoções que trazem uma série de perdas às pessoas, dentre elas, a perda das relações de vizinhança, perda das atividades ocupacionais, além de empobrecimento de famílias por conta da perda do trabalho, moradias em casas de pequenos cômodos, distância do local de trabalho, dificuldade de pagamento de taxas e serviços antes inexistentes na moradia anterior, dentre outros. 
tempo, vinculada às demandas institucionais que valorizam o mercado imobiliário, com clara orientação de minimização de direitos sociais.

\section{Questão Urbana e Habitacional e Pós-graduação em Serviço Social}

Como Área de conhecimento, o Serviço Social foi reconhecido pela Coordenação de Aperfeiçoamento de Pessoal de Nível Superior - CAPES, em 1976, possuindo, hoje, importante produção bibliográfica com base teórica crítica, inclusive, com reconhecimento internacional em países latino-americanos, africanos e europeus (especialmente Portugal e Espanha). Dentre os fatores que impulsionaram esse crescimento e reconhecimento, está o avanço das pesquisas desenvolvidas nos Programas de Pós-Graduação em Serviço Social implantados na década de 1970 e expandidos a partir da década de 1990, com destaque para o crescimento na década de 2000, acompanhando o período de expansão do Sistema Nacional de Pós-graduação (CAPES, 2017).

O relatório da Avaliação Quadrienal (2017), registra que na área 32 na CAPES (Serviço Social) foram avaliados 34 Programas $^{14}$ de Pós-Graduação compondo o Sistema Nacional de Pós-Graduação, com 34 cursos de Mestrado e 18 cursos de Doutorado, sendo a maioria dos Programas concentrados nas regiões sudeste e nordeste $(69,7 \%)^{15}$. Os Programas existentes são ofertados, majoritariamente, pelas Universidades Públicas (78,8\%). Entre estes ,49,4\% dos docentes possuem doutorado em Serviço Social - com pósdoutorado $(17,2 \%)$ no Brasil e no exterior - e titulados principalmente entre 2000-2009 (65\%).

As pesquisas na Área de Serviço Social têm definido como objeto de investigação, grosso modo: a) a natureza da profissão (seu modo de ser e fundamentos históricos, teóricos e metodológicos); b) as expressões da questão social, as respostas do Estado a essas expressões, e as lutas sociais por acesso às políticas públicas; c) um leque ampliado de estudos acadêmicos (sobre o Estado, economia política, financiamento de políticas, questão agrária, urbana e ambiental, migrações, dentre outros). A organização dos pesquisadores em torno da Associação Brasileira de Ensino e Pesquisa em Serviço Social/ABEPSS é um espaço

\footnotetext{
${ }^{14}$ Região Norte: UFAM, UFPA; Região Nordeste: UFMA, FUFPI, UECE, UFRN, UERN, UFPB/JP, UEPB, UFPE, UFRPE, UFAL, FUFSE; Região Sudeste: UFES, EMESCAM, UFRJ, UFF (SERV. SOC. E DESENV. REG), UFF (Política Social), UERJ, PU/CRIO, UFV, UFJF, UNESP/FR, PUC/SP, UNIFESP; Região Sul: UEL, UNIOESTE, UFSC, UFRGS, PUC/RS, UCPEL; Região Centro Oeste: UFMT, PUC/GOIÁS, UNB.

${ }^{15}$ A área de Serviço Social não possui Programas de Pós-Graduação nos seguintes estados da Região Norte (AC, $A P, R O, R R$ e TO), bem como nos estados da BA e MS.
} 
importante de acompanhamento das propostas curriculares do Serviço Social e de discussão de temas de pesquisa. O CNPq possui registro (para o ano de 2018) de 391 Grupos de Pesquisas na Área do Serviço Social, certificados pela instituição.

Dentre esses Grupos, a sondagem realizada na plataforma Lattes/CNPq (Diretório dos Grupos de Pesquisa no Brasil) identificou 24 grupos relacionados ao tema da questão urbana e habitacional. A Região Sudeste concentra o maior número de Programas de PósGraduação na Área de Serviço Social, liderança que também se expressa no número de grupos de pesquisa na temática em exame (12 grupos) (Quadro 1).

Quadro 1 - Grupos de pesquisa relacionados ao tema da questão urbana e habitacional CNPq

\begin{tabular}{|c|c|c|}
\hline REGIÃO / INSTITUIÇÃO & \multirow[t]{2}{*}{ GRUPO } & \multirow[t]{2}{*}{ LÍDER } \\
\hline Região Norte & & \\
\hline $\begin{array}{l}\text { Universidade Federal do } \\
\text { Pará }\end{array}$ & $\begin{array}{c}\text { Grupo de Pesquisa Cidade, Habitação e Espaço } \\
\text { Humano }\end{array}$ & $\begin{array}{l}\text { Joana Valente } \\
\text { Santana }\end{array}$ \\
\hline $\begin{array}{l}\text { Universidade Federal do } \\
\text { Pará }\end{array}$ & $\begin{array}{c}\text { Grupo de pesquisa Sociedade, Território e } \\
\text { Resistências na Amazônia (GESTERRA) }\end{array}$ & $\begin{array}{l}\text { Solange Maria } \\
\text { Gayoso da Costa }\end{array}$ \\
\hline $\begin{array}{l}\text { Universidade Federal do } \\
\text { Pará }\end{array}$ & $\begin{array}{l}\text { Políticas Urbanas e Movimentos Sociais na Amazônia } \\
\text { Globalizada }\end{array}$ & $\begin{array}{l}\text { Sandra Helena } \\
\text { Ribeiro Cruz }\end{array}$ \\
\hline \multicolumn{3}{|l|}{ Região Nordeste } \\
\hline $\begin{array}{l}\text { Universidade Federal do } \\
\text { Maranhão }\end{array}$ & $\begin{array}{c}\text { Grupo de Estudos, Pesquisa e Debates em Serviço } \\
\text { Social e Movimento Social - GSERMS }\end{array}$ & $\begin{array}{c}\text { Josefa Batista } \\
\text { Lopes }\end{array}$ \\
\hline $\begin{array}{c}\text { Universidade Federal do } \\
\text { Piauí }\end{array}$ & Cidade, processos urbanos e políticas públicas & $\begin{array}{c}\text { Antônia Jesuíta } \\
\text { de Lima }\end{array}$ \\
\hline $\begin{array}{l}\text { Universidade Federal de } \\
\text { Pernambuco }\end{array}$ & $\begin{array}{c}\text { Núcleo de Estudos e Pesquisa em Habitação e } \\
\text { Saneamento Ambiental }\end{array}$ & $\begin{array}{c}\text { Rosa Maria } \\
\text { Cortês de Lima }\end{array}$ \\
\hline $\begin{array}{l}\text { Universidade Federal de } \\
\text { Sergipe }\end{array}$ & $\begin{array}{c}\text { Grupo de Estudos e Pesquisas em Trabalho, Questão } \\
\text { Social e Movimento Social (GETEQ) }\end{array}$ & $\begin{array}{l}\text { Tereza Cristina } \\
\text { Santos Martins }\end{array}$ \\
\hline \multicolumn{3}{|l|}{ Região Sudeste } \\
\hline $\begin{array}{l}\text { Universidade Federal do } \\
\text { Espírito Santo }\end{array}$ & $\begin{array}{c}\text { INTERFACES - Grupo de Estudo sobre Políticas Sociais } \\
\text { e Urbanas, Fundo Público e Serviço Social }\end{array}$ & $\begin{array}{l}\text { Maria Helena } \\
\text { Elpidio Abreu }\end{array}$ \\
\hline $\begin{array}{l}\text { Universidade Federal do Rio } \\
\text { de Janeiro }\end{array}$ & $\begin{array}{l}\text { LOCUSS - Núcleo de Pesquisa e Extensão Políticas } \\
\text { Públicas, Território, Lutas Sociais e Serviço Social }\end{array}$ & $\begin{array}{l}\text { Gabriela Maria } \\
\text { Lema Icasuriaga }\end{array}$ \\
\hline $\begin{array}{l}\text { Universidade Federal do Rio } \\
\text { de Janeiro }\end{array}$ & $\begin{array}{c}\mathrm{FACl} \text { - Laboratório de Pesquisa e Extensão Favela e } \\
\text { Cidadania }\end{array}$ & $\begin{array}{c}\text { Maria de Fatima } \\
\text { C. Marques } \\
\text { Gomes }\end{array}$ \\
\hline $\begin{array}{l}\text { Universidade Federal } \\
\text { Fluminense }\end{array}$ & GEPET - Grupo de Estudos e Pesquisas sobre Trabalho & $\begin{array}{c}\text { Maria das Graças } \\
\text { O. P. Lustosa }\end{array}$ \\
\hline $\begin{array}{l}\text { Universidade Federal } \\
\text { Fluminense }\end{array}$ & $\begin{array}{c}\text { Núcleo de Estudos e Pesquisas sobre Educação do } \\
\text { Campo e Movimentos Sociais (NEPEC) }\end{array}$ & $\begin{array}{c}\text { Douglas Ribeiro } \\
\text { Barboza }\end{array}$ \\
\hline $\begin{array}{l}\text { Universidade Federal } \\
\text { Fluminense }\end{array}$ & $\begin{array}{c}\text { Núcleo de Estudos e Pesquisas sobre Favelas e } \\
\text { Espaços Populares (NEPFE) }\end{array}$ & $\begin{array}{c}\text { Francine } \\
\text { Helfreich } \\
\text { Coutinho dos } \\
\text { Santos }\end{array}$ \\
\hline $\begin{array}{l}\text { Universidade Federal } \\
\text { Fluminense }\end{array}$ & $\begin{array}{l}\text { Núcleo de Estudos e Pesquisas sobre Trabalho, } \\
\text { Política, Movimentos Sociais e Serviço Social }\end{array}$ & $\begin{array}{c}\text { Haidee de Caez } \\
\text { Pedroso } \\
\text { Rodrigues }\end{array}$ \\
\hline $\begin{array}{l}\text { Universidade do Estado do } \\
\text { Rio de Janeiro }\end{array}$ & Programa de Estudos de Trabalho e Política & $\begin{array}{c}\text { Isabel Cristina da } \\
\text { Costa Cardoso }\end{array}$ \\
\hline
\end{tabular}




\begin{tabular}{|c|c|c|}
\hline $\begin{array}{l}\text { Pontifícia Universidade } \\
\text { Católica do Rio de Janeiro }\end{array}$ & Laboratório de Estudos Urbanos e Socioambientais & $\begin{array}{c}\text { Rafael Soares } \\
\text { Gonçalves }\end{array}$ \\
\hline $\begin{array}{l}\text { Universidade Federal de Juiz } \\
\text { de Fora }\end{array}$ & Questão social, Território e Serviço Social & $\begin{array}{c}\text { Mônica } \\
\text { Aparecida Grossi } \\
\text { Rodrigues } \\
\end{array}$ \\
\hline $\begin{array}{c}\text { Pontifícia Universidade } \\
\text { Católica de São Paulo } \\
\end{array}$ & $\begin{array}{c}\text { Núcleo de Estudos e Pesquisas sobre Movimentos } \\
\text { Sociais - NEMOS }\end{array}$ & $\begin{array}{l}\text { Rosângela Dias } \\
\text { Oliveira da Paz }\end{array}$ \\
\hline $\begin{array}{l}\text { Universidade Federal de São } \\
\text { Paulo }\end{array}$ & Serviço Social, Trabalho e Cidade & $\begin{array}{l}\text { Maria Rosângela } \\
\text { Batistoni }\end{array}$ \\
\hline \multicolumn{3}{|l|}{ Região Sul } \\
\hline $\begin{array}{l}\text { Universidade Estadual de } \\
\text { Londrina }\end{array}$ & Gestão de Política Social & $\begin{array}{l}\text { Jolinda de } \\
\text { Moraes Alves }\end{array}$ \\
\hline $\begin{array}{l}\text { Universidade Estadual do } \\
\text { Oeste do Paraná }\end{array}$ & $\begin{array}{l}\text { Grupo de Estudo e Pesquisa em Políticas Ambientais e } \\
\text { Sustentabilidade - GEPPAS }\end{array}$ & $\begin{array}{l}\text { Diuslene } \\
\text { Rodrigues da } \\
\text { Silva }\end{array}$ \\
\hline $\begin{array}{l}\text { Universidade Federal do Rio } \\
\text { Grande do Sul }\end{array}$ & $\begin{array}{l}\text { NÚCLEO DE ESTUDOS E PESQUISAS TERRA, } \\
\text { TRABALHO E POLIITICA SOCIAL }\end{array}$ & $\begin{array}{l}\text { Mailiz Garibotti } \\
\text { Lusa }\end{array}$ \\
\hline $\begin{array}{c}\text { Pontifícia Universidade } \\
\text { Católica do Rio Grande do } \\
\text { Sul }\end{array}$ & $\begin{array}{l}\text { Grupo de Pesquisa Cotidiano, Trabalho e Território - } \\
\text { GPsT }\end{array}$ & $\begin{array}{l}\text { Gleny Terezinha } \\
\text { Duro Guimarães }\end{array}$ \\
\hline $\begin{array}{l}\text { Universidade Católica de } \\
\text { Pelotas }\end{array}$ & $\begin{array}{l}\text { Questão agrária, urbana e ambiental e Observatório } \\
\text { dos Conflitos da Cidade }\end{array}$ & $\begin{array}{c}\text { Cristine Jaques } \\
\text { Ribeiro } \\
\end{array}$ \\
\hline
\end{tabular}

Fonte: Elaborado pela autora com base nos dados disponíveis da Plataforma Lattes/CNPq (Diretório dos Grupos de Pesquisa no Brasil) (2018).

O levantamento de dados na página da CAPES (Plataforma Sucupira) demonstrou que no período de 2013 a 2017, em relação às disciplinas ofertadas pelos 34 Programas de Pós-Graduação/Área de Serviço Social, 12 Programas ofertaram 17 disciplinas relacionadas ao tema da questão urbana e habitacional. Os dados demonstram que o PPG da UFPA concentra o maior número de disciplinas (4 no período em estudo), seguido do PPG da PUC/Rio e UFV (com 2 disciplinas, cada Programa) (Quadro 2). Registra-se, ainda, que com exceção do PPG da UFJF, cuja disciplina é obrigatória, todas são ofertadas como disciplinas eletivas. 
Quadro 2 - Disciplinas ofertadas referentes ao tema da questão urbana e habitacional

\begin{tabular}{|c|c|}
\hline REGIÃO/IES/PPG & NOME DISCIPLINA \\
\hline \multicolumn{2}{|l|}{ Região Norte } \\
\hline UFAM & Cidade, sustentabilidade urbana e políticas públicas \\
\hline UFPA & $\begin{array}{l}\text { Cidade capitalista e políticas urbanas } \\
\text { Urbano-rural e lutas sociais no brasil e na Amazônia } \\
\text { Questão urbana e política habitacional na Amazônia } \\
\text { Urbano-rural e movimentos sociais no Brasil e na Amazônia }\end{array}$ \\
\hline \multicolumn{2}{|l|}{ Região Nordeste } \\
\hline FUFPI & Tópico de política pública: questão urbana \\
\hline UFRN & Estudos urbanos, rurais, relações de poder e movimentos sociais \\
\hline UFPE & Questão urbana e serviço social \\
\hline \multicolumn{2}{|l|}{ Região Sudeste } \\
\hline UFRJ & Cultura urbana e movimentos sociais \\
\hline PUCRIO & $\begin{array}{l}\text { Políticas urbanas e direito à cidade } \\
\text { Questões socioambientais urbanas }\end{array}$ \\
\hline UFV & $\begin{array}{l}\text { Políticas públicas de habitação } \\
\text { Espaço e sociedade }\end{array}$ \\
\hline UFJF & Território, sociedade e serviço social \\
\hline $\mathrm{PUC} / \mathrm{SP}$ & $\begin{array}{l}\text { Questão urbana, política habitacional e o trabalho social: fundamentos, } \\
\text { vertentes teóricas e desafios para o trabalho profissional do assistente social }\end{array}$ \\
\hline \multicolumn{2}{|l|}{ Região Sul } \\
\hline UCPEL & Cidades e territorialidades \\
\hline \multicolumn{2}{|l|}{ Região Centro Oeste } \\
\hline UNB & Política social - habitação \\
\hline
\end{tabular}

Fonte: Elaborado pela autora com base nos dados disponíveis da Plataforma Sucupira/CAPES (2018.).

A investigação buscou também evidenciar os autores mais indicados nas referências nas disciplinas (listadas no Quadro 2). Mediante contagem simples dos autores indicados acima de cinco vezes, foi possível verificar que Milton Santos é o autor mais recomendado para leitura nos PPG em estudo (citado 15 vezes), seguido de David Harvey, Henri Lefebvre e Ermínia Maricato (citados 14 vezes cada um) (Quadro 3). A incidências dos autores listados no Quadro 3 demonstra que há uma perspectiva crítica na formação pós-graduada em Serviço Social, no que se refere ao ensino da temática da questão urbana e habitacional. Nesta direção, David Harvey é, provavelmente, o geógrafo alinhado ao pensamento marxista mais lido e incorporado, mundialmente, aos debates sobre a crítica radical à apropriação do solo pelas empresas capitalistas, bem como sobre as lutas sociais que alimentam a construção da justiça social, sintetizada na luta pelo direito à cidade.

Destaca-se que dos/as 12 autores/as mais citados (Quadro 3), a única autora da área de Serviço Social é Maria de Fátima Cabral Marques Gomes, docente da UFRJ, pesquisadora que é uma referência nos estudos da questão urbana e habitacional, articulada ao trabalho profissional do Assistente Social ${ }^{16}$.

\footnotetext{
${ }^{16}$ Ver Gomes e Pelegrino (2005), Gomes e Barbosa (2010) e Gomes et al. (2013).
} 
Quadro 3 - Autores mais indicados nas referências das Disciplinas PPG / Área de Serviço Social.

\begin{tabular}{|c|c|}
\hline NOME DO/A AUTOR/A & $\begin{array}{c}\text { NÚMERO DE VEZES } \\
\text { INDICADO NAS } \\
\text { REFERÊNCIAS }\end{array}$ \\
\hline SANTOS, Milton & 15 \\
\hline HARVEY, David & 14 \\
\hline LEFEBVRE, Henri & 14 \\
\hline MARICATO, Ermínia & 14 \\
\hline ENGELS, Friedrich & 8 \\
\hline GOMES, Maria de Fátima Cabral Marques & 8 \\
\hline RIBEIRO, Luiz César de Queiroz & 8 \\
\hline LOJKINE, Jean & 5 \\
\hline ROLNIK, Raquel & 5 \\
\hline RIBEIRO, Ana Clara Torres & 5 \\
\hline BONDUKI, Nabil & 5 \\
\hline ARANTES, Otília; VAINER, Carlos; MARICATO, Ermínia \\
(org.)
\end{tabular}

Fonte: Elaborado pela autora com base nos dados disponíveis da Plataforma Sucupira/CAPES (2018.).

O levantamento sobre a produção discente referente aos 34 PPG/Área de Serviço Social, no período de 2013 a 2017, identificou 2.545 trabalhos de conclusão de curso. Destes, 91 (3,6\%) trabalhos discutem temas acerca da questão urbana e habitacional, sendo 75 trabalhos nível mestrado e 16 em doutorado (Quadro 4). Além disso, desses 91 trabalhos, 73 (80,2\%) enfatizam especificamente a questão da habitação.

Quadro 4 - Trabalhos de Conclusão de Curso IES/PPG Área de Serviço Social - Trabalhos de Conclusão - Tema Questão Urbana e Habitacional - 2013 a 2017.

\begin{tabular}{|c|c|c|c|c|c|c|c|}
\hline REGIÃO/IES & 2013 & 2014 & 2015 & 2016 & 2017 & $\begin{array}{c}\text { TOTAL DE } \\
\text { TRABALHOS } \\
\text { DE } \\
\text { CONCLUSÃO - } \\
2013 \text { a } 2017\end{array}$ & $\begin{array}{l}\text { TRABALHOS DE } \\
\text { CONCLUSÃO - } \\
\text { TEMA QUESTÃO } \\
\text { URBANA E } \\
\text { HABITACIONAL }\end{array}$ \\
\hline \multicolumn{8}{|l|}{ Região Norte } \\
\hline 1. UFAM (M) & 9 & 14 & 15 & 10 & 13 & 61 & 2 \\
\hline 2. UFPA (M/D) & 15 & 16 & 17 & 11 & 10 & 69 & 11 \\
\hline \multicolumn{8}{|l|}{ Região Nordeste } \\
\hline 1.UFMA (M/D) & 15 & 22 & 16 & 14 & 26 & 93 & 2 \\
\hline 2. FUFPI (M/D) & 16 & 17 & 20 & 7 & 15 & 75 & 2 \\
\hline 3. UECE (M) & 4 & 8 & 11 & 10 & 10 & 43 & 2 \\
\hline 4. UFRN (M/D) & 16 & 17 & 8 & 10 & 13 & 64 & 2 \\
\hline 5. UERN (M) & 0 & 0 & 0 & 10 & 13 & 23 & 0 \\
\hline 6. UFPB/JP (M) & 17 & 14 & 27 & 19 & 19 & 96 & 2 \\
\hline 7.UEPB (M) & 0 & 0 & 12 & 11 & 9 & 32 & 0 \\
\hline 8.UFPE (M/D) & 23 & 25 & 21 & 20 & 30 & 119 & 4 \\
\hline 9.UFRPE (M) & 0 & 0 & 3 & 19 & 11 & 33 & 2 \\
\hline 10.UFAL (M) & 5 & 14 & 13 & 10 & 10 & 52 & 0 \\
\hline 11.FUFSE (M) & 8 & 14 & 9 & 11 & 6 & 48 & 1 \\
\hline Região Sudeste & & & & & & & \\
\hline
\end{tabular}




\begin{tabular}{|c|c|c|c|c|c|c|c|}
\hline 1.UFES (M/D) & 11 & 13 & 9 & 13 & 14 & 60 & $\mathbf{0}$ \\
\hline 2.EMESCAM (M) & 16 & 24 & 10 & 29 & 23 & 102 & 0 \\
\hline 3.UFRJ (M/D) & 38 & 31 & 37 & 27 & 26 & 159 & 8 \\
\hline $\begin{array}{l}\text { 4.UFF (M) -- SERV. SOC. E } \\
\text { DESENV. REG. }\end{array}$ & 0 & 9 & 9 & 5 & 4 & 27 & 1 \\
\hline 5.UFF (M/D) Política Social & 20 & 26 & 12 & 15 & 13 & 86 & 2 \\
\hline 6.UERJ (M/D) & 28 & 24 & 27 & 27 & 33 & 139 & 4 \\
\hline 7.PUCRIO (M/D) & 20 & 17 & 24 & 16 & 15 & 92 & 8 \\
\hline 8.UFV (M/D) & 10 & 15 & 19 & 28 & 17 & 89 & 4 \\
\hline 9.UFJF (M) & 12 & 13 & 19 & 15 & 15 & 74 & 6 \\
\hline 10.UNESP/FR (M/D) & 25 & 29 & 24 & 26 & 27 & 131 & 1 \\
\hline 11.PUC/SP (M/D) & 35 & 42 & 52 & 45 & 32 & 206 & 7 \\
\hline 12.UNIFESP (M) & 0 & 0 & 0 & 0 & 0 & 0 & 0 \\
\hline \multicolumn{8}{|l|}{ Região Sul } \\
\hline 1.UEL (M/D) & 9 & 11 & 11 & 18 & 12 & 61 & 3 \\
\hline 2.UNIOESTE (M) & 0 & 0 & 3 & 14 & 8 & 25 & 1 \\
\hline 3.UFSC (M/D) & 15 & 6 & 15 & 14 & 23 & 73 & 2 \\
\hline 4.UFRGS (M) & 0 & 0 & 0 & 0 & 0 & 0 & 0 \\
\hline 5.PUC/RS (M/D) & 27 & 25 & 25 & 15 & 26 & 118 & 5 \\
\hline 6.UCPEL (M/D) & 17 & 17 & 17 & 7 & 21 & 79 & 2 \\
\hline \multicolumn{8}{|l|}{ Região Centro Oeste } \\
\hline 1.UFMT (M) & 15 & 10 & 15 & 9 & 8 & 57 & 1 \\
\hline 2.PUCGOIÁS (M) & 12 & 18 & 11 & 13 & 13 & 67 & 2 \\
\hline 3.UNB (M/D) & 19 & 16 & 20 & 16 & 21 & 92 & 4 \\
\hline \multicolumn{6}{|l|}{ Total } & 2.545 & 91 \\
\hline
\end{tabular}

Fonte: Elaborado pela autora com base nos dados disponíveis da Plataforma Sucupira/CAPES (2018).

Ressalta-se que em termos quantitativos, dos 91 trabalhos que tratam do tema da questão urbana e habitacional, o Programa de Pós-Graduação em Serviço Social da UFPA é o que apresentou o maior número $(11)^{17}$, seguido da UFRJ e PUC/Rio que apresentaram, cada um, 08 trabalhos e a PUC/SP, com 07 trabalhos (Gráfico 1$)^{18}$.

\footnotetext{
${ }^{17}$ Importante sinalizar que o Programa de Apoio à Reforma Urbana, um programa de extensão e pesquisa da UFPA, foi criado em 1992 e vem atuando na assessoria aos movimentos sociais na Região Metropolitana de Belém, particularmente na discussão do saneamento e habitação.

${ }^{18}$ Alguns programas iniciaram suas atividades em 2013, a exemplo da UERN, UEPB, UFRPE, UNIOESTE, o que pode justificar a menor frequência de trabalhos no tema pesquisado. A UNIFESP e a UFRGS iniciaram em 2016.
} 
Gráfico 1 - Trabalhos de conclusão de curso por IES / Área de avaliação Serviço Social Tema questão urbana e habitacional - 2013/2017.

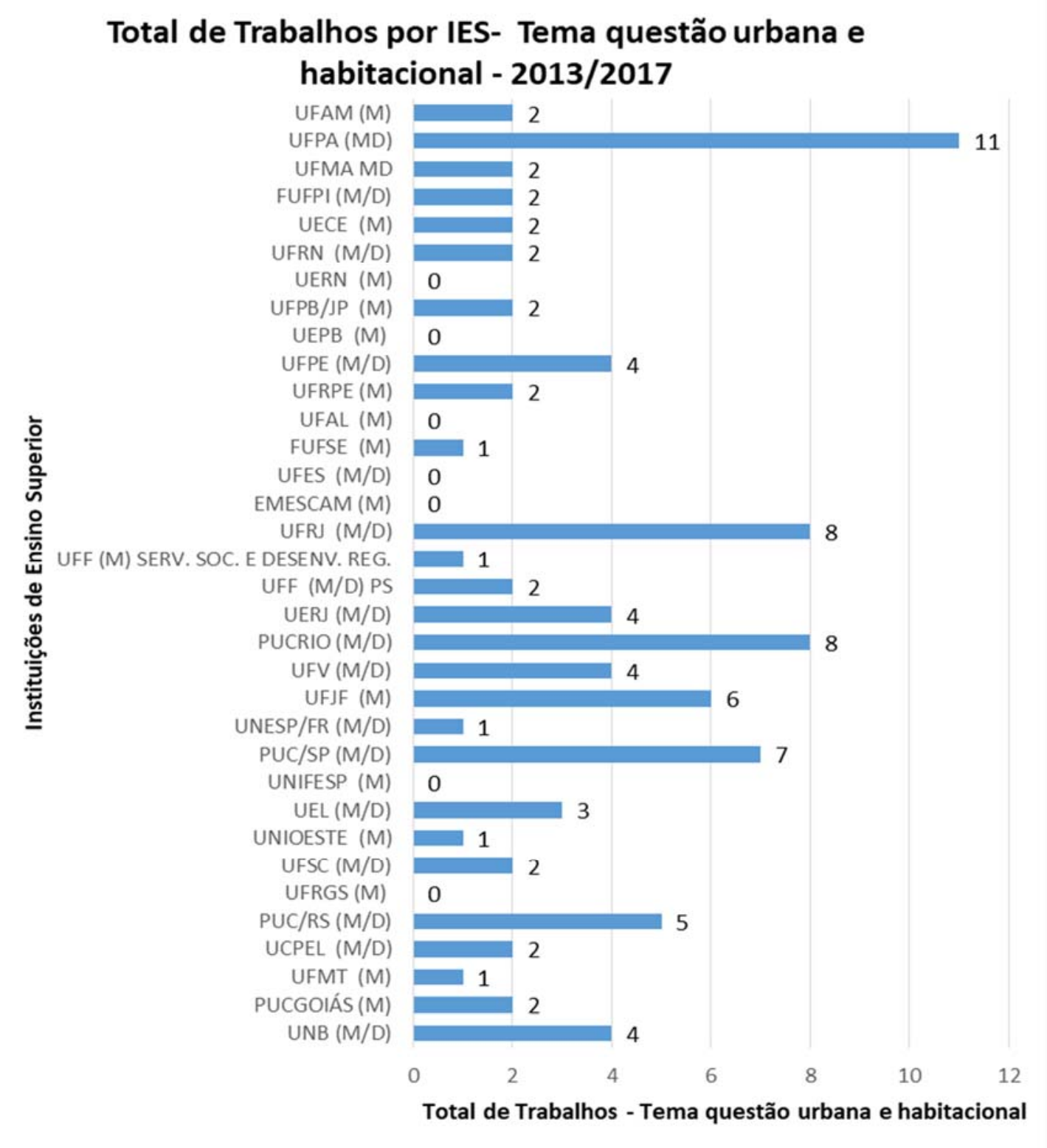

Fonte: Elaborado pela autora com base nos dados disponíveis da Plataforma Sucupira/CAPES (2018).

A sondagem procurou, também, identificar se os/as autores/as relacionaram o tema da questão urbana e habitacional ao trabalho profissional do Assistente Social, sendo possível constatar que dos 91 trabalhos, apenas 19 (21\%) fazem essa articulação (Gráfico 2). 
Gráfico 2 - Trabalhos de conclusão - Tema questão urbana e habitacional - Atuação Profissional - 2013/2017.

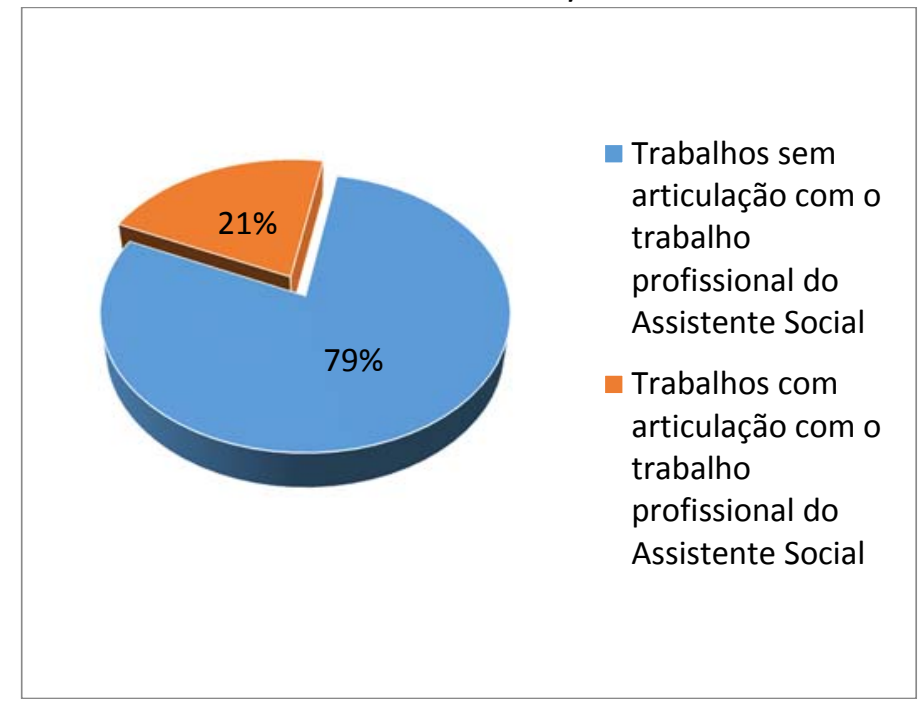

Fonte: Elaborado pela autora com base nos dados disponíveis da Plataforma Sucupira/CAPES (2018).

Uma breve análise dos trabalhos identificados no levantamento demonstra que a Pós-Graduação em Serviço Social no Brasil está em consonância com o projeto ético-político do Serviço Social brasileiro. Os temas de pesquisa sobre a questão urbana e habitacional expressam a intencionalidade dos pesquisadores em buscar a interpretação crítica sobre a apropriação privada do solo, a qual é inerente ao modo de produção capitalista, revelando a desigualdade no uso da cidade pelas diferentes frações de classe social. Os trabalhos de pesquisa apontam o papel contraditório do Estado capitalista em atender, majoritariamente às empresas capitalistas e, ao mesmo tempo, atender minimamente aos trabalhadores empobrecidos moradores das favelas, baixadas, que são os espaços possíveis (e inadequados) para a reprodução social da grande maioria das pessoas ${ }^{19}$.

O espaço urbano é um lugar da luta de classes. Para o embelezamento das cidades para o capital, o Estado constitui um suporte essencial, disponibilizando vultosos recursos com a infraestrutura urbana. Por esse motivo, vários trabalhos discutiram criticamente a mercantilização das cidades, os grandes eventos esportivos (como a Copa do Mundo e os Jogos Olímpicos), os grandes projetos de infraestrutura urbana (PROMABEN, PROSAMIN) e seu corolário, as remoções de moradores que passam por projetos de reassentamento ou remanejamento urbano, motivo pelo qual uma quantidade expressiva dos trabalhos discute a categoria de segregação socioespacial.

\footnotetext{
${ }^{19}$ Três estudos tratam da intervenção estatal em habitação na Argentina, Colômbia e Portugal.
} 
No conjunto dos trabalhos, destacam-se os estudos que demonstram a precariedade habitacional (em pequenas cidades ou metrópoles), com um destaque para a análise das contradições inerentes ao Programa Minha Casa Minha Vida (PMCMV) que, se por um lado, contribuiu com a diminuição do déficit habitacional, por outro lado, apresenta problemas no atendimento de serviços urbanos. Assim, os trabalhos enfatizam as condições de moradia, a inadequação na infraestrutura urbana dos espaços onde foram construídos os residenciais (ausência e ou ineficiência de equipamentos urbanos, distância do centro, problemas com transporte, insegurança etc.), ou seja, para a questão da precariedade dos serviços urbanos que afeta a vida dos moradores atendidos por esse Programa, precariedade essa que se soma às condições de pobreza e alto nível de desemprego.

A esse processo contraditório de intervenção urbana estatal voltam-se os trabalhos de pesquisa que tratam da atuação profissional do Assistente Social, onde são evidenciados os dilemas da profissão, cuja intervenção é mediada tanto pela orientação ética e política em favor dos trabalhadores, como pelos interesses das empresas capitalistas. O dilema está em que os projetos urbanísticos, que removem os pobres e que requerem ao trabalho profissional do assistente social, são envoltos no discurso de participação e organização comunitária, educação ambiental e geração de trabalho e renda, quando na verdade, em essência, trata-se do controle e manutenção dos pobres em lugares inadequados à moradia e em condições mínimas para exploração da força de trabalho.

Alguns estudos destacam as potencialidades da política de Habitação de Interesse Social, ao exemplo dos Planos Locais de Interesse Social (PLHIS) os Planos Diretores, discutindo assim os desafios e possibilidades da atuação profissional na política urbana e habitacional. Por sua vez, o percentual de trabalhos encontrados no levantamento ( $21 \%$ de 91 trabalhos) que tratam da atuação do assistente social na questão urbana e habitacional, demonstra que a área, embora tenha avançado significativamente, carece de maior discussão nesse tema.

Um conjunto de trabalhos expõe as condições de vida da classe trabalhadora, que passa por mudança de moradia por conta das intervenções urbanas estatais. Assim, parte importante das pesquisas realizam estudos sobre pós-ocupação, avaliação de impactos socioeconômicos de moradores que sofrem processos de remanejamento, reassentamento, através do Programa de Aceleração do Crescimento/PAC ou PMCMV. 
Por outro lado, os trabalhos discutem a organização política dos moradores na luta pela moradia, a questão da resistência social, atuação de movimentos sociais, conflitos socioambientais, as contradições no acesso à cidade. Há uma forte incidência no tema do direito à moradia e ao direito à cidade no conjunto dos trabalhos, o que sugere que o projeto profissional do Serviço Social possui uma perspectiva crítica, mas não apenas isso; que esse projeto articula as dimensões teórico-metodológicas, ético-políticas e técnicooperativas da profissão, visando à construção de uma sociabilidade para além do capital.

\section{Considerações Finais}

O Serviço Social no Brasil, como profissão e como área de conhecimento, tem avançado consideravelmente nos estudos sobre a questão social e suas expressões, as contradições de classe na ordem burguesa, a atuação do Estado em favor das frações de classe dominante, o papel das políticas sociais nessas contradições e a atuação profissional, especialmente nessas políticas.

A questão urbana e habitacional é um dos temas que vem sendo estudado pela área de Serviço Social, considerando-se a demanda da atuação profissional nas políticas urbanas e habitacionais, mediada pelas contradições da produção do espaço urbano capitalista, a desigualdade no acesso ao solo urbano, a ocupação do espaço para moradia pela classe trabalhadora em lugares inadequados, a organização política dos movimentos sociais, dentre outros.

A Associação Brasileira de Ensino e Pesquisa em Serviço Social, o Conselho Federal de Serviço Social e os Programas de Pós-Graduação em Serviço Social têm contribuído, significativamente, para a formação e trabalho profissional dos assistentes sociais em uma perspectiva crítica e articulada ao projeto ético-político. Trata-se de um esforço de apreensão das contradições da produção do espaço urbano capitalista, do papel do Estado na conformação do espaço em favor das empresas capitalistas e da atuação profissional nessas contradições com base em princípios éticos e políticos em favor dos trabalhadores.

O levantamento na página da CAPES e do CNPq que teve por objetivo apresentar uma discussão sobre a questão urbana e habitacional no âmbito da pós-graduação em Serviço Social no Brasil nos últimos cinco anos, revelou que:

- Na plataforma lattes do CNPq (para o ano de 2018) encontram-se registrados 391 Grupos de Pesquisas na Área do Serviço Social e destes 24 grupos estudam temas relativos à 
questão urbana e habitacional, sendo que a maioria desses Grupos encontram-se na Região Sudeste, a qual concentra o maior número de programas de pós-graduação na Área de Serviço Social;

- Na plataforma Sucupira da CAPES, no período de 2013 a 2017, 12 dos 34 Programas de Pós-Graduação na Área de Serviço Social ofertaram 17 disciplinas (16 eletivas e 01 obrigatória) relacionadas ao tema da questão urbana e habitacional, sendo que o PPG da UFPA ofertou o maior número de disciplinas, seguido do PPG da PUC/Rio e UFV. A investigação sobre as referências nestas disciplinas demonstrou que o geógrafo Milton Santos é o autor mais indicado para leitura, seguido de David Harvey, Henri Lefebvre e Ermínia Maricato. A professora Maria de Fátima Cabral Marques Gomes, da UFRJ foi a única autora da Área de Serviço Social citada dentre os 12 autores/as mais recomendados.

- Quanto à produção discente, o levantamento na Plataforma Sucupira revelou que no período de 2013 a 2017, foram cadastrados 2.545 trabalhos de conclusão de curso pelos PPG e desse total, 3,6\% (91 trabalhos) tratam da temática sobre a questão urbana e habitacional (75 nível mestrado e 16 em doutorado). A ênfase no tema da habitação foi encontrada em 73 desses 91 trabalhos, correspondendo a 80,2\%.

- Em termos de distribuição dos trabalhos de Conclusão por Regiões e Instituições de Ensino Superior no Brasil, dos 91 estudos que tratam do tema da questão urbana e habitacional, a UFPA apresentou o maior número (11), vindo na sequência, UFRJ e PUC/Rio com 08 trabalhos e PUC/SP com 07 trabalhos.

- Dos 91 trabalhos referidos, 19 (21\%) fazem essa articulação com a atuação profissional do Assistente Social na questão urbana e habitacional.

- Os 91 trabalhos identificados tratam, dentre outros: do espaço urbano como lugar da luta de classes; embelezamento de cidades em favor das empresas capitalistas; atuação do estado em favor dessas empresas mediante produção da infraestrutura urbana; mercantilização das cidades; remoções de moradores (mediante reassentamento, remanejamento urbano, indenizações); segregação socioespacial; precariedade habitacional; contradições do Programa Minha Casa Minha Vida (PMCMV); atuação profissional do Assistente Social na política urbana e habitacional com enfoque nos dilemas da atuação contraditória entre os interesses de classe (orientação ética e política em favor dos trabalhadores e pelos interesses das empresas capitalistas); política habitacional de interesse social e as possibilidades de atuação profissional nessas políticas; estudos sobre 
condições de vida dos trabalhadores (avaliação de impactos socioeconômicos); organização política dos moradores na luta pela moradia e resistência política; conflitos socioambientais; direito à moradia e direito à cidade.

À guisa de síntese, pode-se afirmar que embora apenas 3,6\% dos 2.545 trabalhos produzidos pelos discentes da pós-graduação tenham enfatizado a questão urbana e habitacional, há uma articulação dos temas estudados ao projeto ético-político do Serviço Social brasileiro. O levantamento demonstra que a pós-graduação da área tem procurado contribuir com a formação e o trabalho profissional de Assistentes Sociais, com a necessária articulação entre as dimensões teórico-metodológicas, ético-políticas e técnico-operativas, em consonância com as diretrizes curriculares do Serviço Social.

São esses elementos indispensáveis para que os profissionais da área atuem em projetos urbanísticos, posicionando-se em defesa dos direitos da classe trabalhadora, conforme preconiza o Projeto Ético-político da profissão.

\section{Referências}

BONDUKI, N. G. Origens da habitação social no Brasil. Análise Social, Lisboa, v. 29, n. 127, p. 711-732, 1994. Disponível em: $<$ http://analisesocial.ics.ul.pt/documentos/1223377539C9uKS3pp5Cc74XT8.pdf>. Acesso em: 20 out. 2018.

BONDUKI, N. G.; ROLNIK, R. Periferia da grande São Paulo: reprodução do espaço como expediente de reprodução da força de trabalho. In: MARICATO, E. (Org.). A produção capitalista da casa (e da cidade) no Brasil industrial. São Paulo: Alfa-Ômega, 1979. p. $117-$ 154.

CAPES - COORDENAÇÃO DE APERFEIÇOAMENTO DE PESSOAL DE NÍVEL SUPERIOR. Relatório de Avaliação 2013-2017/Quadrienal 2017. Brasília: CAPES, 2017.

CARDOSO, I. C. C. Cidade capitalista e política urbana no Brasil do século XXI: como pensar a realidade periurbana? In: SANTANA, J. V.; HOLANDA, A. C. G.; MOURA, A. S. F. (Org.). A questão da habitação em municípios periurbanos na Amazônia. Belém: EdUFPA, 2012. p. 2952.

CFESS - CONSELHO FEDERAL DE SERVIÇO SOCIAL. Atuação de assistentes sociais na política urbana: subsídios para reflexão. Brasília: CFESS, 2016. (Trabalho e projeto profissional nas políticas sociais, v. 5).

CFESS - CONSELHO FEDERAL DE SERVIÇO SOCIAL. Na Copa, comemorar o que? CFESS Manifesta. Brasília, 15 maio 2014. Disponível em:

<http://www.cfess.org.br/arquivos/2014cfessmanifesta-diaAS2014-site.pdf>. Acesso em: 15 out. 2018. 
DENALDI, R. Assentamentos precários: identificação, caracterização e tipos de intervenção. In: BRASIL. Ministério das Cidades. Secretaria Nacional de Habitação. Curso à distância: planos locais de habitação de interesse social. Brasília: Secretaria Nacional de Habitação, 2009. p. 107-131. Disponível em: <www.cidades.gov.br/secretariasnacionais/secretaria-dehabitacao/biblioteca>. Acesso em: 11 abr. 2010.

DINIZ, T. M. R. G. Renovação urbana e desigualdades socioespaciais: contribuição para o debate. In: GOMES, M. F. C. M.; MAIA, R.; CARDOSO, I. C. C.; FRANÇA, B. A. (Org.). Renovação urbana, mercantilização da cidade e desigualdades socioespaciais. Rio de Janeiro: Mauad X, 2013. p. 221-233.

ENGELS, F. A situação da classe trabalhadora na Inglaterra. Porto: Afrontamento, 1975.

GOMES, M. F. C. M. et al. (Org.). Renovação urbana, mercantilização da cidade e desigualdades socioespaciais. Rio de Janeiro: Mauad X, 2013.

GOMES, M. F. C. M.; BARBOSA, Maria José de Souza. Cidade e sustentabilidade: mecanismos de controle e resistência. Rio de Janeiro: Terra Vermelha, 2010.

GOMES, M. F. C. M.; PELEGRINO, A. I. C. (Org.). Política de habitação popular e trabalho social. Rio de Janeiro: DP\&A, 2005.

HARVEY, D. A produção capitalista do espaço. São Paulo: Annablume, 2005.

LEFEBVRE, H. A cidade do capital. Rio de Janeiro: DP\&A, 1999.

LOJKINE, J. O Estado capitalista e a questão urbana. São Paulo: Martins Fontes, 1997.

MARICATO, E. Autoconstrução, a arquitetura possível. In: MARICATO, E. (Org.). A produção capitalista da casa (e da cidade) no Brasil industrial. São Paulo: Alfa-Ômega, 1979. p. 71-93.

MARICATO, E. Brasil, cidades: alternativas para a crise urbana. Petrópolis: Vozes, 2001.

MOTA, A. E. Serviço Social brasileiro: insurgência intelectual e legado político. In: SILVA, M. L. O. (org.). Serviço Social no Brasil: história de resistências e de ruptura com o conservadorismo. São Paulo: Cortez, 2016. p. 165-182.

SANTANA, J. V. Desenho ideológico do BID: modelo de gestão no Promaben em Belém, Pará. Revista Katálysis, Florianópolis, v. 15, n. 1, p. 21-31, jan./jun. 2012.

SANTANA, J. V. Gestão de cidades no Brasil: estratégias e orientações do Banco Interamericano de Desenvolvimento. Campinas: Papel Social, 2013.

SANTOS JUNIOR, O. A.; SANTOS, C. Impactos econômicos dos megaeventos: investimentos públicos, participação privada e incertezas. In: SEMINÁRIO NACIONAL MEGAEVENTOS, 2013, Rio de Janeiro. Anais [...]. [S. I.]: Observatório das Metrópoles. 2013. Disponível em: http://direitoamoradia.org/wp-content/uploads/2014/02/impactos-economicos-dosmegaeventos-observatorio-das-metr\%C3\%B3poles.pdf. Acesso em: 10 maio 2014.

SANTOS, M. A urbanização brasileira. São Paulo: Hucitec, 1993. 
SILVA, M. O. S. Política habitacional brasileira: verso e reverso. São Paulo: Cortez, 1989.

SOUZA, A. K. Vila da Barca, das palafitas ao conjunto habitacional: análise sobre a (im)permanência dos moradores na área. 2011. 203 f. Dissertação (Mestrado em Servico Social) - Universidade Federal do Pará, Belém, 2011.

TOPALOV, C. Da questão social aos problemas urbanos: os reformadores e a população das metrópoles em princípios do século XX. In: RIBEIRO, L. C. Q.; PECHMAN, R. (Org.). Cidade, povo e nação: gênese do urbanismo moderno. Rio de Janeiro: Civilização Brasileira, 1996. p. 23-51.

VALLADARES, L. P. (Org.). A invenção da favela: do mito de origem a favela.com. Rio de Janeiro: FGV, 2005.

VALLADARES, L. P. (Org.). Passa-se uma casa: análise do programa de remoções de favelas do Rio de Janeiro: Zahar, 1980.

VALLADARES, L. P. (Org.). Repensando a habitação no Brasil. Rio de Janeiro: Zahar Editores, 1983.

VILLAÇA, F. O que todo cidadão precisa saber sobre habitação. São Paulo: Global, 1986.

(Cadernos de educação política; Série sociedade e Estado, n. 16). 